\title{
PENGUKURAN PARAMETER SIMPLISIA DAN EKSTRAK ETANOL DAUN PATIKALA (Etlingera elatior (Jack) R.M. Sm) ASAL KABUPATEN ENREKANG SULAWESI SELATAN
}

\author{
Yuri Pratiwi Utami, Siska Sisang, Asril Burhan \\ Sekolah Tinggi IImu Farmasi Makassar
}

\section{Kata Kunci :}

Daun Patikala (Etlingera elatior (Jack) R.M. Sm), Pengukuran Parameter spesifik dan non spesifik, Simplisia, Ekstrak

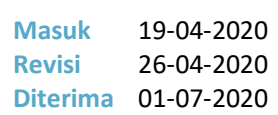

DOI: 10.20956/mff.v24i1.9831

\section{Korespondens}

\section{Yuri Pratiwi Utami}

yuriutami88@gmail.com

Sekolah Tinggi Ilmu Farmasi Makassar

Jl. Perintis Kemerdekaan Km. 13,7, Daya, Makassar, 90242 Indonesia

Copyright

C 2020 Majalah Farmasi

Farmakologi Fakultas Farmasi Makassar

Diterbitkan tanggal

01 Juli 2020

Dapat Diakses Daring Pada: http://journal.unhas.ac.id/index.php/mff

\begin{abstract}
ABSTRAK
Daun Patikala (Etlingera elatior (Jack) RM. Smith) diketahui memiliki banyak efek farmakologis sebagai obat tradisional. Bahan baku obat tradisional perlu standarisasi. Standarisasi simplisia dan ekstrak etanol daun patikala dilakukan untuk mengendalikan mutu dan keamanannya sebagai bahan baku obat tradisional. Penetapan standar mutu simplisia dan ekstrak meliputi parameter spesifik dan parameter non spesifik. Pengamatan makroskopik pada simplisia menunjukkan serbuk daun patikala berwarna kehijauan, pertulangan daun menyirip, daunnya tunggal, lanset, ujung dan pangkal runcing tetapi rata, panjang daun sekitar $20-30 \mathrm{~cm}$ dan lebar $5-15 \mathrm{~cm}$. Organoleptik dari ekstrak etanol daun patikala yaitu kental, berwarna hitam kehijauan, berbau khas dan berasa pahit. Fragmen pengenal simplisia daun patikala berupaepidermis bawah, serabut ,epidermis atas dengan stomata tipe anomositik, serabut berkas pembuluh. Ekstrak daun patikala mengandung senyawa alkaloid, steroid, flavonoid dan tanin.Kadar senyawa terlarut dalam air pada simplisia sebesar $12,392 \%$ dan pada ekstrak sebesar $23,555 \%$, sedangkan kadar senyawa terlarut dalam etanol pada simplisia sebesar $7,078 \%$ dan pada ekstrak sebesar $22,260 \%$. Kadar air dalam simplisia dan ekstrak masing-masing $\leq 10 \%$. Kadar abu total dalam simplisia sebesar 14,12\% dan dalam ekstrak sebesar 9,06\%, kadar abu tidak larut asam dalam simplisia sebesar $7,44 \%$ dan dalam ekstrak sebesar $1 \%$. Susut pengeringan pada simplisia sebesar $11,461 \%$ dan pada ekstrak sebesar 57,564\%. Bobot jenis ekstrak sebesar 1,0087 g/ml. Total cemaran bakteri dan kapang pada ekstrak memenuhi syarat dengan nilai masing-masing sebesar $120 \mathrm{koloni} / \mathrm{g}$ dan $890 \mathrm{koloni} / \mathrm{g}$.
\end{abstract}

\section{PENDAHULUAN}

Obat tradisional telah lama dikenal dan digunakan oleh semua lapisan masyarakat di Indonesia untuk tujuan pengobatan maupun perawatan kesehatan. Pemanfaatan tanaman berkhasiat obat tersebut terus berkembang dan diwariskan ke generasi selanjutnya. Obat tradisional dibuat dalam bentuk ekstrak karena tanaman obat tidak lagi praktis jika digunakan dalam bentuk bahan utuh (simplisia). Penggunaan obat tradisional secara umum dinilai lebih aman (1). Bahkan Organisasi Kesehatan Dunia (World Health Organization) mendorong, menganjurkan dan mempromosikan obat tradisioanl dalam program perawatan kesehatan nasional karena obat ini mudah tersedia dengan biaya renda, aman dan masyarakat memiliki keyakinan di dalamnya. Melihat hal ini maka perlu dilakukan penetapan standar mutu dan keamanan dari bahan baku obat tradisional.

Salah satu tumbuhan obat yang dapat digunakan sebagai obat tradisional adalah daun Patikala(Etlingera elatior (Jack) RM. Smith). Patikala merupakan salah satu family Zingiberacea dan merupakan tanaman asli Indonesia. Tumbuhan ini pada masyarakat umumnya digunakan untuk memperbanyak asi, deodorant, dan daunnya digunakan sebagai obat luka. Menurut Hasbah et al, (2005), tanaman patikala dapat dipakai untuk mengobati penyakitpenyakit yang tergolong berat yaitu kanker dan tumor. Tanaman patikala, alkaloid, flavonoid, steroid, saponin dan minyak atsiri yang diduga memiliki mengandung senyawa bioaktif seperti polifenol potensi sebagai antioksidan (2).

Mengingat obat tradisional dan berbagai tanaman memiliki peran penting dalam bidang kesehatan bahkan bisa menjadi produk andalan Indonesia maka perlu dilakukan upaya penetapan standar mutu dan keamanan ekstrak tanaman obat. Standarisasi secara normatif ditujukan untuk memberikan efikasi yang terukur secara farmakologis dan menjamin keamanan konsumen. Standarisasi obat herbal meliputi dua aspek yaitu aspek spesifik dan aspek non spesifik. Aspek parameter spesifik yakni berfokus pada senyawa atau golongan senyawa yang bertanggung jawab terhadap aktivitas farmakologis. Sedangkan, aspek parameter non spesifik yakni berfokus aspek kimia, mikrobiologi, dan fisis yang akan mempengaruhi keamanan konsumen dan stabilitas (3).

Simplisia sebagai bahan baku ekstrak harus memenuhi persyaratan monografinya yang tertera dalam buku Material Medika Indonesia dan produk ekstrak juga harus memenuhi persyaratan parameter standar spesifik dan non spesifik (4). Oleh karenanya perlu dilakukan untuk mengetahui standar mutu dan keamanan dari bahan baku obat tradisional.

Berdasarkan latar belakang yang telah diuraikan maka akan dilakukan penelitian parameter pengukuran simplisia dan ekstrak etanol daun Patikala asal enrekang untuk menjamin mutu 
daun Patikala yang akan digunakan sebagai obat tradisional.

\section{METODE PENELITIAN}

\section{Alat dan Bahan}

Alat-alat yang digunakan yaitu aluminium foil, alat-alat gelas (Pyrex), alat destilasi, autoklaf, cawan petri, cawan porselin, chamber, desikator, inkubator, kurs porselin, lampu UV 254 $\mathrm{nm}$ dan $365 \mathrm{~nm}$, lempeng KLT, oven, piknometer, seperangkat alat maserasi (wadah dan pengaduk), timbangan analitik, dan tanur.

Bahan-bahan yang digunakan yaitu daun patikala, asam asetat anhidrat, asam klorida , asam sulfat, aquades, besi III klorida, etanol $70 \%$, eter, etil asetat, kloroform, lempeng silika GF 254, medium PDA (Potato Dextrose Agar), medium NA (Nutrien Agar) n-heksan, natrium klorida, pereaksi Dragendorff, pereaksi Liebermann, pereaksi Mayer, pereaksi Wagner, serbuk Mg dan toluena.

\section{Penyiapan Simplisia}

Tumbuhan daun Patikala diperoleh dari kabupaten Enrekang Sulawesi Selatan. Patikala dideterminasi di Pusat Penelitian Biologi - Lembaga Ilmu Pengetahuan Indonesia (LIPI), Bogor. Bagian tanaman yang digunakan adalah helaian daun. Helai daun kemudian dicuci bersih dengan air mengalir, dirajang, lalu dikeringkan dalam lemari pengering selama 3 x 24 jam. Daun yang telah kering diserbukan tanpa menyebabkan kerusakan atau kehilangan kandungan kimia.

\section{Pembuatan Ekstrak}

Serbuk simplisia daun Patikala 500 gram dimaserasi dengan menggunakan etanol $70 \%$ sebanyak 5 L. Simplisia dimasukkan ke dalam wadah maserasi dibasahi dengan pelarut etanol 70\% lalu didiamkan \pm 15 -30 menit. Setelah itu, penyari ditambahkan hingga semua simplisia terendam sempurna. Kemudian didiamkan di tempat yang terlindung dari sinar matahari selama $3 \times 24$ jam dan dilakukan pengadukan sesekali. Hasil maserasi disaring dengan kain saring. Filtrat yang diperoleh, kemudian dipekatkan.

\section{Pengukuran Parameter}

Parameter Spesifik

\section{Pemeriksaan Organoleptik}

Uji organoleptik, dilakukan dengan pengenalan secara fisik menggunakan panca indera untuk mendeskripsikan bentuk, bau, warna, dan rasa (4).

\section{Uji Makroskopik}

Uji makroskopik dilakukan dengan menggunakan kaca pembesar atau tanpa alat. Cara ini dilakukan untuk mencari kekhususan morfologi dan warna simplisia daun patikala.

\section{Uji Mikroskopik}

Uji mikroskopik dilakukan terhadap serbuk simplisia dan diamati fragmen pengenal daun patikala secara umum yang dilakukan melalui pengamatan dibawah mikroskop, menggunakan kloralhidrat LP

\section{Kadar senyawa larut air}

Sejumlah 2,5 g simplisia dan ekstrak (W1) dilarutkan dengan $50 \mathrm{~mL}$ kloroform P $(2,5 \mathrm{ml}$ kloroform dalam $1000 \mathrm{~mL}$ aquadest) selama 24 jam, menggunakan labu bersumbat sambil dikocok selama 6 jam kemudian didiamkan selama 18 jam dan disaring. Filtrat yang diperoleh kemudian diuapkan hingga kering dalam cawan penguap yang telah ditarar $\left(\mathrm{W}_{0}\right)$, residunya kemudian dipanaskan pada suhu $105^{\circ} \mathrm{C}$ hingga bobot tetap $\left(\mathrm{W}_{2}\right)(4,5)$.

\section{Kadar Senyawa Larut dalam Etanol}

Sejumlah 2,5 g simplisia dan ekstrak $\left(\mathrm{W}_{1}\right)$ dilarutkan dengan $50 \mathrm{~mL}$ etanol $95 \%$ selama 24 jam, menggunakan labu bersumbat sambil dikocok selama 6 jam kemudian didiamkan selama 18 jam dan disaring cepat untuk menghindari penguapan etanol. Filtrat yang diperoleh kemudian diuapkan hingga kering dalam cawan penguap yang telah ditarar $\left(\mathrm{W}_{0}\right)$, residunya kemudian dipanaskan pada suhu $105^{\circ} \mathrm{C}$ hingga bobot tetap $\left(\mathrm{W}_{2}\right)(4,5)$.

\section{Uji Kandungan Kimia \\ Uji Alkaloid}

Ekstrak dicampur dengan $5 \mathrm{~mL}$ kloroform dan $5 \mathrm{~mL}$ amoniak kemudian dipanaskan, dikocok dan disaring. Asam sulfat $2 \mathrm{~N}$ sebanyak 5 tetes ditambahkan pada masing-masing filtrat, kemudian kocok dan didiamkan. Bagian atas dari masingmasing filtrat diambil dan diuji dengan pereaksi Mayer, Wagner dan Dragendorf. Terbentuknya endapan putih, cokelat dan jingga menunjukkan adanya alkaloid (6).

\section{Uji flavonoid}

Ekstrak dicampur dengan $3 \mathrm{~mL}$ etanol $70 \%$ lalu dikocok, dipanas-kan dan dikocok lagi kemudian disaring. Filtrat yang diperoleh ditambahkan serbuk Mg 0,1 g dan 2 tetes $\mathrm{HCl}$ pekat. Terbentuknya warna merah pada lapisan etanol menunjukkan adanya flavonoid (6).

\section{Uji Tanin}

Ekstrak disari dengan $10 \mathrm{~mL}$ air kemudian disaring, filtratnya diencer-kan dengan air sampai tidak berwar-na. Larutan diambil sebanyak $2 \mathrm{~mL}$ dan ditambahkan 2 tetes $\mathrm{FeCl} 1 \%$. Terbentuknya warna cokelat kehijauan atau biru kehitaman menunjukkan adanya tanin (6).

\section{Uji Terpenoid dan steroid}

Ekstrak dicampur dengan $3 \mathrm{~mL}$ kloroform atau $3 \mathrm{~mL}$ etanol $70 \%$ dan ditambah $2 \mathrm{~mL}$ asam sulfat pekat dan $2 \mathrm{~mL}$ asam asetat anhidrat. Perubahan warna dari ungu ke biru atau hijau menunjukkan adanya senyawa steroid dan terbentuknya warna kecokelatan antar permukaan menunjukkan adanya senyawa terpenoid (6).

\section{Uji Saponin}

Ekstrak dimasukkan ke dalam tabung reaksi, air panas sebanyak $10 \mathrm{~mL}$ ditambahkan, dinginkan dan kemudian dikocok kuat-kuat selama 10 detik. Positif mengandung saponin jika terbentuk buih setinggi $1-10 \mathrm{~cm}$ selama tidak kurang dari 10 menit dan pada penambahan 1 tetes $\mathrm{HCl} 2 \mathrm{~N}$, buih tidak hilang (7).

\section{Pola Kromatogram (KLT)}

Ekstrak kasar dilarutkan dengan etanol 70\% kemudian ditotolkan pada lempeng silika yang sudah diaktifkan dan kemudian dielusi menggunakan eluen n- heksan dan etil asetat dengan perbandingan $8: 2$ Hasil penampakan noda dapat dilihat melalui lampu UV $254 \mathrm{~nm}, 365 \mathrm{~nm}$ dan juga dengan menggunakan pereaksi semprot $\mathrm{H}_{2} \mathrm{SO}_{4} \quad 10 \%$ kemudian dihitung nilai Rf (7).

\section{Parameter Non Spesifik}

\section{Penetapan Susut Pengeringan}

Sebanyak 2 g ekstrak dimasukkan ke dalam kurs porselin tertutup yang sebelumnya telah dipanaskan selama 30 menit pada suhu $105^{\circ} \mathrm{C}$ dan telah ditarer. Ekstrak diratakan dalam kurs dengan menggoyangkan kurs hingga terbentuk lapisan tebal 5-10 mm, lalu ditimbang. Dimasukkan ke dalam oven lalu tutupnya dibuka, dikeringkan pada suhu $105^{\circ} \mathrm{C}$ hingga 
diperoleh bobot tetap. Didinginkan dalam desikator dan dihitung nilai persentasinya (4).

\section{Penentuan Bobot Jenis}

Bobot jenis ekstrak ditentukan dengan hasil pengenceran ekstrak 5\% dalam pelarut etanol dengan menggunakan piknometer. Piknometer yang digunakan harus bersih, kering dan telah dikalibrasi. dengan menetapkan bobot piknometer dan bobot air yang baru didihkan pada suhu $25^{\circ} \mathrm{C}$. Suhu diatur hingga ekstrak cair lebih kurang $20^{\circ} \mathrm{C}$, lalu dimasukkan kedalam piknometer. Diatur suhu ekstrak yang ada di dalam piknometer hingga mencapai $25^{\circ} \mathrm{C}$, setelah itu ditimbang. Dihitung dengan (4).

\section{Penentuan Kadar Air (4)}

Penetapan kadar air dilakukan dengan cara destilasi toluen. Toluen yang digunakan dijenuhkan dengan air terlebih dahulu. Kemudian, simplisia dan ekstrak masing-masing ditimbang secara seksama sebanyak $5 \mathrm{~g}$ dan dimasukkan ke dalam labu alas bulat, lalu ditambahkan toluen yang telah dijenuhkan. Dengan hati-hati labu dipanaskan selama 15 menit, setelah toluen mulai mendidih, penyulingan diatur 2 tetes/ detik, lalu 4 tetes/ detik. Setelah semua tersuling, dilanjutkan pemanasan selama 5 menit. Setelah itu, tabung didinginkan hingga mencapai suhu kamar. Volume air di baca setelah toluen dan air memisah dengan sempurna.

\section{Kadar Abu}

\section{Kadar Abu Total}

Sebanyak 2 g simplisia dan ekstrak, ditimbang seksama (Wi), dimasukkan ke dalam kurs yang telah ditimbang (W0). Setelah itu, ekstrak dimasukkan dalam oven pada suhu \pm $25^{\circ} \mathrm{C}$ hingga arang hilang. Lalu, didinginkan di dalam desikator dan ditimbang berat abu $\left(\mathrm{W}_{2}\right)(8)$.

\section{Kadar Abu Tidak Larut Asam}

Abu yang diperoleh dari penetapan kadar abu, dididihkan dengan $25 \mathrm{~mL}$ asam klorida encer selama 5 menit. Bagian tidak larut asam dikumpulkan dan disaring dengan kertas saring bebas abu yang sebelumnya telah ditimbang, kurs dibilas dengan air panas. Abu yang tersaring, dimasukkan kembali ke dalam kurs yang sama. Lalu, dimasukkan dalam oven sampai arang hilang, dan ditimbang hingga memperoleh bobot tetap ( $\left.\mathrm{W}_{3}\right)$ (8).

\section{Penentuan Cemaran Mikroba (22)}

Sebanyak 1 g ekstrak dilarutkan dalam $10 \mathrm{~mL}$ larutan pengencer, yaitu Aqua Pro Injection, lalu dikocok hingga homogen untuk mendapatkan pengenceran $10^{-1}$. Disiapkan 3 tabung, dimasukkan $9 \mathrm{~mL}$ larutan pengencer pada masingmasing tabung. Dipipet sebanyak $1 \mathrm{~mL}$ dari pengenceran 10 1 ke dalam tabung pertama, dikocok hingga homogen untuk mendapatkan hasil pengenceran $10^{-2}$, perlakuan sama dilakukan hingga diperoleh hasil pengenceran $10^{-3}$ dan hasil pengenceran $10^{-4}(4)$.

\section{Angka Lempeng Total (ALT)}

Dipipet $1 \mathrm{~mL}$ dari tiap pengenceran ke dalam cawan petri yang steril (triplo), dengan menggunakan pipet yang berbeda dan steril untuk masing-masing pengenceran. Ke dalam masing-masing cawan petri dituangkan $15 \mathrm{~mL}$ media NA (Nutrient Agar) yang telah dicairkan, lalu cawan petri digoyang agar suspensi tercampur rata. Setelah media memadat, cawan petri diinkubasi pada suhu $37^{\circ} \mathrm{C}$ selama 24 jam dengan posisi terbalik.

\section{Penentuan Total Kapang}

Dipipet $1 \mathrm{~mL}$ dari tiap pengenceran ke dalam cawan petri yang steril (triplo), dengan menggunakan pipet yang berbeda dan steril untuk masing-masing pengenceran. Ke dalam masing-masing cawan petridituangkan $15 \mathrm{~mL}$ media PDA (Potato Dextrose Agar) yang telah dicairkan, lalu cawan petri digoyang agar suspensi tercampur rata. Setelah media memadat, cawan petri diinkubasi pada suhu $25^{\circ} \mathrm{C}$ selama 5 hari dengan posisi terbalik. Kemudian diamati.

\section{HASIL DAN PEMBAHASAN}

Pada penelitian ini digunakan sampel daun patikala dari Kabupaten Enrekang Provinsi Sulawesi Selatan. Daun patikala tersebut memiliki potensi untuk mengobati penyakit-penyakit yang tergolong berat yaitu kanker dan tumor serta beberapa jenis luka. Sehingga dilakukan pengukuran standar mutu bahan baku simplisia dan ekstrak daun patikala. Tujuan dari standardisasi sendiri, yaitu untuk menjamin standar mutu dan keamanan ekstrak tanaman obat bagi konsumen. Penetapan standar mutu yang dilakukan meliputi beberapa parameter spesifik dan non spesifik. Parameter spesifik, yaitu pemeriksaan organoleptik dan uji kandungan kimia ekstrak, kromatogram, uji larut dalam pelarut tertentu sedangkan parameter non spesifik, yaitu penentuan bobot jenis, susut pengeringan, kadar air, kadar abu, dan cemaran mikroba.

Penentuan nilai standardisasi dilakukan sebagai salah satu acuan untuk mengetahuiapakah ekstrak tersebut memenuhi standar dan persyaratan yang telah ditetapkan, dalam hal ini digunakan acuan yang bersifat umum, karena belum adanya acuan resmi tersendiri dari daun patikala.

Sampel yang digunakan pada penelitianini adalah serbuk simplisia dan ekstrak etanol daun patikala. Ekstrak diperoleh dari hasil ekstraksi dengan menggunakan metode maserasi dengan etanol $70 \%$. Ekstrak kental yang diperoleh sebanyak $52,744 \mathrm{~g}$ dengan persen rendemen sebesar 10,5489\%. Pemilihan maserasi sebagai metode ekstraksi yang digunakan didasari dari sifat beberapa senyawa yang diduga terkandung di dalam daun Patikala yang tidak stabil pada suhu tinggi sehingga penggunaan metode ekstraksi panas dianggap kurang tepat. Selain itu metode maserasi juga tidak membutuhkan peralatan yang rumit dan mudah dalam pengerjaannya. Penggunaan etanol $70 \%$ sebagai larutan penyari karena memiliki kemampuan menyari senyawa pada rentang polaritas yang lebar mulai dari senyawa polar hingga non polar, tidak toksik dibanding dengan pelarut organik yang lain, lebih mudah diuapkan dibanding air, tidak mudah ditumbuhi mikroba dan relatif murah (3).

Parameter Spesifik

\section{Pemeriksaan Organoleptik}

Pemeriksaan organoleptik dilakukan pengamatan sampel meliputi bentuk, warna, bau dan rasa. Paremeter organoleptik ekstrak bertujuan memberikan pengenalan awal terhadap simplisia dan ekstrak menggunakan panca indera dengan mendeskripsikan bentuk, warna, bau, dan rasa (4). Hasil pemeriksaan organoleptik terlampir pada tabel.

\begin{tabular}{cc} 
Tabel 1. Pemeriksaan Organoleptik serbuk Simplisia Daun Patikala \\
\hline Pengamatan & Hasil \\
\hline Bentuk & Serbuk \\
Warna & Cokelat kehijauan \\
Bau & Berbau Khas \\
Rasa & Pahit \\
\hline
\end{tabular}

\section{Uji Makroskopik}

Pengujian makroskopik dilakukan terhadap simplisia yang bertujuan untuk mencari kekhususan bentuk morfologi dan warna simplisia daun patikala (9). Hasil Pemeriksaan 
makroskopik menunjukkan simplisia daun patikala berwarna hijau, pertulangan daun menyirip, Daunnya tunggal, lanset, ujung dan pangkal runcing tetapi rata, panjang daun sekitar $20-30 \mathrm{~cm}$ dan lebar $5-15 \mathrm{~cm}$.

Tabel 2. Pemeriksaan Organoleptik ekstrak Simplisia Daun Patikala

\begin{tabular}{cc}
\hline Pengamatan & Hasil \\
\hline Bentuk & Kental \\
Warna & Hitam kehijauan \\
Bau & Berbau Khas \\
Rasa & Pahit \\
\hline
\end{tabular}

\section{Uji Mikroskopik}

Pengujianmikroskopik dilakukan terhadap serbuk simplisia daun patikala. Serbuk simplisia daun patikala menunjukkan fragmen seperti pada gambar. Pengujian mikroskopik bertujuan untuk menentukan fragmen pengenal yang terdapat pada daun patikala, sehingga dapat mencegah pemalsuan simplisia (9).

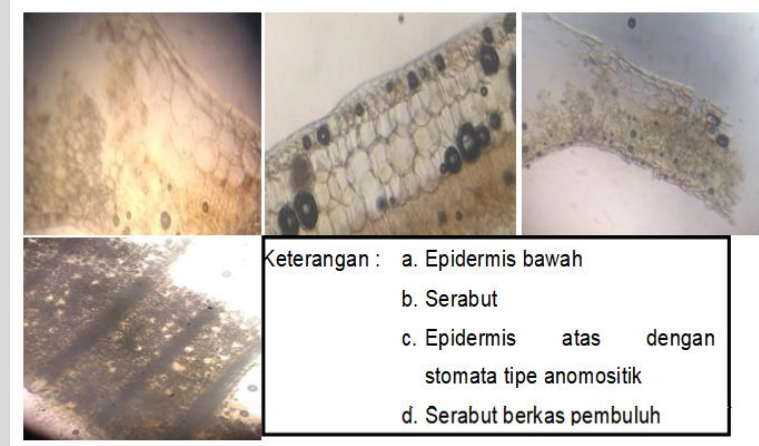

Gambar 1. Hasil pengujian mikroskopik simplisia daun kecombrang

\section{Uji Kandungan Kimia}

Penapisan fitokimia bertujuan untuk mengetahui keberadaan golongan senyawa metabolit sekunder yang ada dalam simplisia dan ekstrak, serta dapat pula jadi gambaran kandungan ekstrrak secara kualitatif (10). Uji kandungan kimia bertujuan untuk memberikan gambaran awal komposisi kandungan kimia (10). Uji kandungan kimia dilakukan terhadap simplisia dan ekstrak etanol daun patikala, hasil yang diperoleh menunjukkan bahwa simplisia mengandung senyawa flavonoid, tanin, saponin, dan steroid sedangkan pada ekstrak etanol daun patikala mengandung senyawa alkaloid, steroid/terpenoid, flavonoid dan tanin (Tabel 3 \& 4).

\begin{tabular}{|c|c|c|c|}
\hline \multicolumn{2}{|c|}{ Golongan Senyawa } & \multirow{2}{*}{$\begin{array}{l}\text { Hasil } \\
\text { Tidak ada endapan }\end{array}$} & \multirow{2}{*}{$\begin{array}{l}\text { Ket } \\
-\end{array}$} \\
\hline & P. Mayer & & \\
\hline \multirow[t]{2}{*}{ Alkaloid } & P. Wagner & Tidak ada endapan & - \\
\hline & P. Dragendorf & Tidak ada endapan & - \\
\hline $\begin{array}{l}\text { Steroid/ } \\
\text { Terpenoid }\end{array}$ & & Biru kehijauan & + \\
\hline Flavanoid & & Kuning & + \\
\hline Tanin & & Cokelat kehijauan & + \\
\hline Saponin & & berbusa & + \\
\hline
\end{tabular}

\section{Penetapan Kadar Sari Terlarut Pada Pelarut Air dan Etanol}

Penetapan kadar senyawa terlarut dalam pelarut air dan etanol ini bertujuan sebagai perkiraan banyaknya kandungan senyawa-senyawa aktif yang bersifat polar (larut dalam air) dan bersifat polar - non polar (larut dalam etanol) (3). Pada simplisia, kadar senyawa yang terlarut dalam pelarut air dan etanol adalah masing-masing sebesar 12, 39
$\%$ dan 7, $08 \%$. Kadar senyawa pada ekstrak yang terlarut dalam pelarut air dan etanol adalah masing-masing sebesar $23,555 \%$ dan 22,260 \%. Hasil yang diperoleh memperlihatkan bahwa senyawa senyawa dari daun patikala lebih banyak larut dalam pelarut air dibandingkan etanol. Hal ini menunjukkan senyawa polar yang terkandung dalam daun patikala lebih banyak dibandingkan senyawa non polar.

\begin{tabular}{|c|c|c|c|}
\hline \multicolumn{2}{|c|}{ Golongan Senyawa } & \multirow{2}{*}{$\begin{array}{l}\text { Hasil } \\
\text { Endapan putih }\end{array}$} & \multirow{2}{*}{$\begin{array}{l}\text { Ket } \\
+\end{array}$} \\
\hline \multirow{3}{*}{ Alkaloid } & P. Mayer & & \\
\hline & P. Wagner & Endapan cokelat & + \\
\hline & P. Dragendorf & Endapan hijau & - \\
\hline $\begin{array}{l}\text { Steroid/ } \\
\text { Terpenoid }\end{array}$ & & Berwarna hijau & + \\
\hline Flavanoid & & Berwarna Merah & + \\
\hline Tanin & & Cokelat kehijauan & + \\
\hline Saponin & & Tidak berbusa & - \\
\hline
\end{tabular}

\begin{tabular}{cccccc}
\multicolumn{1}{c}{ Tabel 5. Hasil Uji Kandungan Kimia Ekstrak Etanol Daun Patikala } \\
\hline Pengujian & Sampel & \multicolumn{5}{c}{ Kadar (\%) } \\
\cline { 2 - 6 } & & I & II & III & $\begin{array}{c}\text { Rerata } \\
\text { (\%) }\end{array}$ \\
\hline Sari Larut & Simplisia & 8,650 & 14,775 & 13,750 & 12,392 \\
Air & Ekstrak & 34,303 & 22,078 & 14,283 & 23,555 \\
Sari Larut & Simplisia & 6,294 & 9,250 & 5,688 & 7,078 \\
\cline { 2 - 6 } Etanol & Ekstrak & 34,497 & 17,063 & 15,221 & 22,260 \\
\hline
\end{tabular}

\section{Profil Kromatografi Lapis Tipis}

Pengujian KLT dilakukan untuk memberikan gambaran komposisi kandungan kimia yang terdapat dalam ekstrak etanol daun patikala (4). Komponen tersebut di identifikasi dengan cara membandingkan nilai Rf komponen. Rf menyatakan perbandingan antara jarak yang ditempuh oleh suatu komponen dalam ekstrak dan jarak yang ditempuh eluen yaitu n-heksan dan etil asetat $(8: 2)$. Adanya beberapa noda pada ekstrak daun patikala dengan nilai Rf yang barbeda secara kualitatif dapat menunjukkan adanya beberapa senyawa yang terkandung dalam ekstrak tersebut.

\begin{tabular}{|c|c|c|c|c|c|c|}
\hline \multirow{3}{*}{ Sampel } & \multicolumn{6}{|c|}{ Profil KLT bercak noda } \\
\hline & \multicolumn{2}{|c|}{ UV 254} & \multicolumn{2}{|c|}{ UV 365} & \multicolumn{2}{|c|}{$\mathrm{H}_{2} \mathrm{SO}_{4} 10 \%$} \\
\hline & Rf & Warna & Rf & Warna & Rf & Warna \\
\hline \multirow{6}{*}{$\begin{array}{l}\text { Ekstrak } \\
\text { etanol } \\
\text { daun } \\
\text { patikala }\end{array}$} & 0,05 & $\begin{array}{c}\text { Cokelat } \\
\text { kehitaman }\end{array}$ & 0,14 & Merah & 0,07 & Ungu \\
\hline & 0,27 & $\begin{array}{c}\text { Cokelat } \\
\text { kehitaman }\end{array}$ & 0,21 & Merah & 0,12 & Ungu \\
\hline & 0,38 & $\begin{array}{c}\text { Cokelat } \\
\text { kehitaman }\end{array}$ & 0,34 & Merah & 0,27 & Ungu \\
\hline & 0,54 & $\begin{array}{c}\text { Cokelat } \\
\text { kehitaman }\end{array}$ & 0,49 & Hijau & 0,34 & Ungu \\
\hline & \multirow{2}{*}{0,74} & Cokelat & 0,63 & Biru & 0,43 & Ungu \\
\hline & & kehitaman & 0,78 & Biru & 0,52 & Cokelat \\
\hline
\end{tabular}

\section{Parameter Non-Spesifik}

\section{Uji Susut Pengeringan}

Susut pengeringan merupakan salah satu parameter non spesifik yang bertujuan untuk memberikan batasan maksimal (rentang) tentang besarnya senyawa yang hilang pada proses pengeringan. Parameter susut pengeringan pada dasarnya adalah pengukuran sisa zat setelah pengeringan pada temperatur $105^{\circ} \mathrm{C}$ sampai berat konstan, yang 
dinyatakan sebagai nilai persen (4). Nilai susut pengeringan yang diperoleh dari simplisia dan ekstrak etanol daun patikala asal kabupaten Enrekang Sulawesi Selatan adalah sebesar 11,461 \% dan 57,564\%. Massa yang dapat hilang karena pemanasan ini meliputi molekul air, minyak atsiri dan pelarut etanol.

\begin{tabular}{|c|c|c|c|c|c|}
\hline \multirow{2}{*}{ Pengujian } & \multirow{2}{*}{ Sampel } & \multicolumn{4}{|c|}{ Kadar (\%) } \\
\hline & & 1 & II & III & Rerata (\%) \\
\hline \multirow{2}{*}{$\begin{array}{c}\text { Susut } \\
\text { pengeringan }\end{array}$} & Simplisia & 11,493 & 9,523 & 13,368 & 11,461 \\
\hline & Ekstrak & 44,060 & 76,274 & 52,564 & 57,564 \\
\hline
\end{tabular}

\section{Uji Kadar Abu}

Tujuan dilakukannya pengujian kadar abu adalah untuk memberikan gambaran kandungan mineral internal dan eksternal yang berasal dari proses awal sampai terbentuknya ekstrak (4). Kadar abu total dalam simplisia sebesar 14,12\% dan dalam ekstrak sebesar 9,06\%. Kadar abu untuk simplisia dan ekstrak etanol daun patikala ini cukup tinggi. Tingginya kadar abu menunjukkan tingginya kandungan mineral internal di dalam daun patikala itu sendiri. Semakin tinggi kadar abu yang diperoleh maka kandungan mineral dalam bahan juga semakin tinggi. Mineral diperlukan oleh manusia, seperti kalsium, fosfor dan magnesium untuk pertumbuhan tulang. Natrium dan klorida untuk cairan tubuh, besi untuk pembentukan hemoglobin dan sel darah merah (11). Beda halnya dengan mineral toksik (logamberat) sepertimerkuri, timbal, tembaga, cadmium dan stronsium. Akumulasi logam berat di dalam tubuh manusia dalam jangka waktu lama dapat mengganggu system peredaran darah, urat syaraf dan kerja ginjal.

Kadar abu tidak larut asam mencerminkan adanya kontaminasi mineral atau logam yang tidak larut asam dalam suatu produk. Kadar abu tidak larut asam dalam simplisia sebesar 7,44 \% dan dalam ekstrak sebesar1\%. Tingginya kadar abu tidak larut dalam asam menunjukkan adanya kandungan silikat yang berasal dari tanah atau pasir, tanah dan unsure logam perak, timbale dan merkuri (12).

\begin{tabular}{|c|c|c|c|c|c|}
\hline \multirow[b]{2}{*}{ Pengujian } & \multirow[b]{2}{*}{ Sampel } & \multicolumn{4}{|c|}{ Kadar (\%) } \\
\hline & & 1 & II & III & $\begin{array}{c}\text { Rerata } \\
\text { (\%) }\end{array}$ \\
\hline Kadar Abu & Simplisia & 14,10 & 14,18 & 14,09 & 14,12 \\
\hline Total & Ekstrak & 9,14 & 9,09 & 8,96 & 9,06 \\
\hline $\begin{array}{l}\text { Kadar Abu } \\
\text { Tidak Larut }\end{array}$ & Simplisia & 7,53 & 7,32 & 7,47 & 7,44 \\
\hline Asam & Ekstrak & 1,04 & 0,93 & 1,03 & 1,00 \\
\hline
\end{tabular}

\section{Penetapan Bobot Jenis}

Bobot jenis didefinisikan sebagai perbandingan kerapatan suatu zat terhadap kerapatan air dengan nilai massa per satuan volume. Penentuan bobot jenis ini bertujuan untuk memberikan gambaran kandungan kimia yang terlarut pada suatu ekstrak (12). Pengukuran bobot jenis ekstrak etanol daun Patikala ditentukan dengan menggunakan piknometer. Ekstrak yang digunakan adalah ekstrak yang telah diencerkan $5 \%$ dengan air. Bobot jenis yang diperoleh dari pengenceran ekstrak daun patikala sebesar 1,0087 g/mL.

Penetapan Kadar Air

Kadar air merupakan parameter untuk menetapkan residu air setelah proses pengeringan. Pada pengujian kadar air simplisia dan ekstrak etanol daun patikala digunakan metode destilasi toluen, yang pada prinsipnya menggunakan toluen jenuh air. Kadar air yang diperoleh pada simplisia dan ekstrak masing-masing sesuai dengan syarat mutu yaitu $\leq$ 10\%. Ekstrak kental memilki kadar air antara 5 - 30\% (13). Penentuan kadar air juga terkait dengan kemurnian ekstrak. Kadar air yang terlalu tinggi (> 10\%) menyebabkan tumbuhnya mikroba yang akan menurunkan stabilitas ekstrak (14).

\begin{tabular}{|c|c|c|c|c|c|c|}
\hline \multirow{2}{*}{ Pengujian } & \multicolumn{5}{|c|}{ Hasil (g/mL) } & \multirow{2}{*}{$\begin{array}{l}\text { Rerata } \\
(\mathrm{g} / \mathrm{mL})\end{array}$} \\
\hline & \multicolumn{2}{|c|}{1} & \multicolumn{2}{|l|}{ II } & II & \\
\hline Bobot jenis & \multicolumn{2}{|c|}{1,0068} & 1,0005 & \multicolumn{2}{|c|}{1,0189} & 1,0087 \\
\hline \multicolumn{7}{|c|}{$\begin{array}{l}\text { Tabel 10. Hasil pengujian kadar air simplisia dan ekstrak etanol daun } \\
\text { patikala }\end{array}$} \\
\hline \multirow{2}{*}{ Pengujian } & \multirow{2}{*}{ Sampel } & \multicolumn{4}{|c|}{ Kadar (\%) } & Syarat \\
\hline & & 1 & II & III & $\begin{array}{c}\text { Rerata } \\
\text { (\%) }\end{array}$ & RI, 2014) \\
\hline \multirow{2}{*}{ Kadar Air } & Simplisia & 1,9994 & 1,9992 & 1,9990 & 1,9992 & \multirow{2}{*}{$\leq 10$} \\
\hline & Ekstrak & 2,9992 & 2,9994 & 2,995 & 2,9978 & \\
\hline
\end{tabular}

\section{Uji Cemaran Mikroba}

Pengujian cemaran bakteri dan kapang merupakan salah satu uji untuk kemurnian ekstrak (15). Tujuannya untuk memberikan jaminan bahwa ekstrak tidak mengandung cemaran mikroba dan jamur melebihi batas yang ditetapkan (16). Hasil penelitian menunjukkan cema-ran bakteri dan kapang dalam ekstrak etanol daun patikala masing-masing sebanyak $120 \mathrm{koloni} / \mathrm{g}$ dan $890 \mathrm{koloni} / \mathrm{g}$. Hasil ini sesuai dengan peraturan Kepala Badan Pengawas Obat dan Makanan Republik Indonesia tentang Persyaratan Mutu Obat Tradisional, bahwa batas maksimum cemaran bakteri yaitu $\leq$ $10.000 \mathrm{koloni} / \mathrm{g}$ dan untuk kapang yaitu $\leq 1.000 \mathrm{koloni} / \mathrm{g}$.

\begin{tabular}{|c|c|c|}
\hline Parameter & $\begin{array}{c}\text { Total cemaran } \\
\text { (Koloni/g) }\end{array}$ & $\begin{array}{l}\text { Syarat (koloni/g) } \\
\text { (BPOM RI, 2014) }\end{array}$ \\
\hline Cemaran bakteri & 120 & $\leq 10.000$ \\
\hline Cemaran kapang & 890 & $\leq 1000$ \\
\hline
\end{tabular}

Pencemaran ini dapat terjadi selama proses pengolahan sampel hingga menjadi ekstrak dan juga dapat terjadi selama masa penyimpanan ekstrak yang kemungkinan besar mendapat kontaminasi dari udara di sekitar tempat penyimpanan.

\section{KESIMPULAN}

Parameter spesifik; nama latin dari tumbuhan patikala yaitu Etlingera elatior (Jack) RM. Smith, Simplisia daun patikala berwarna kehijauan, pertulangan daun menyirip, Daunnya tunggal, lanset, ujung dan pangkal runcing tetapi rata, panjang daun sekitar 20-30 cm dan lebar 5-15 cm. Ekstrak etanol daun patikala berkonsistensi kental, berwarna hitamkehijauan, berbau khas dan berasa pahit. Pemeriksaan mikroskopik serbuk simplisia daun patikala memperlihatkan fragmen berupa epidermis bawah, serabut ,epidermis atas dengan stomata tipe anomositik, serabut berkas pembuluh. Kadar senyawa larut air pada simplisia 12,392 \% dan kadar senyawa larut etanol 7,078 \%, sedangkan senyawa yang larut air pada ekstrak $23,555 \%$ dan kadar senyawa larut etanol $22,260 \%$. Simplisia daun patikala mengandung senyawa flavonoid, tanin, saponin, dan steroid sedangkan pada ekstrak etanol daun patikala mengandung senyawa alkaloid, steroid/terpenoid, flavonoid dan tanin 
Parameter non spesifik; perolehan kadar air pada simplisia dan ekstrak masing-masing $\leq 10 \%$. Susut pengeringan yang diperoleh pada simplisia $11,461 \%$ dan pada ekstrak 57,564 $\%$. Hasil kadar abu total pada simplisia didapatkan $14,12 \%$ dan pada ekstrak 9,06\%, serta hasil kadar abu tidak larut asam pada simplisia 7,44 \% dan pada ekstrak 1\%. Perolehan bobot jenis ekstrak $1,0087 \mathrm{~g} / \mathrm{mL}$. Total cemaran bakteri 120 koloni/g dan total cemaran kapang sebanyak 890 koloni/g.

\section{UCAPAN TERIMA KASIH}

Terima kasih kepada Sekolah Tinggi Ilmu Farmasi Makassar yang memberikan kesempatan melakukan penelitian dan mengembangkan penelitian khususnya bahan alam.

\section{DAFTAR PUSTAKA}

1. Wasito, H., 2011, Obat Tradisional Kekayaan Indonesia, Graha Ilmu, Yogyakarta

2. Ningtyas, Rina, 2010, Uji Antioksidant dan Antibakteri Ekstrak Air Daun Kecombrang (Etlingera elatior (Jack) R.M. Smith'. UIN Syarif Hidayatullah ,Jakarta.

3. Saifudin Aziz, Rahayu Viesa, Teruna, Hilwan, Yuda. 2011, Standardisasi bahan obat alam, Edisi pertama. Graha Ilmu, Yogyakarta.

4. Ditjen POM, 2000,Parameter Standar Umum Ekstrak Tumbuhan Obat.DepartemenKesehatan RI, Jakarta
5. jide, M.N.,2006,Mikrobiologi dan Parasitologi Dasar, Laboratorium Mikrobiologi Farmasi Universitas Hasanuddin, Makassar, Indonesia.

6. Harbone,J.B. Metode Fitokimia, Penuntun cara modern menganalisis Tumbuhan,Terbitan kedua, ITB ,Bandung

7. epkes Republik Indonesia, 1985, Cara pembuatan simplisia. DepKes RI ,Jakarta.

8. Saifudin Aziz, Rahayu Viesa, Teruna, Hilwan, Yuda. 2011, Standardisasi bahan obat alam, Edisi pertama. Graha Ilmu, Yogyakarta.

9. Eliyanoor, B., 2012, Penuntun Praktikum Farmakognosi, Edisi II, Buku Kedokteran EGC, Jakarta, Indonesia.

10. Guntarti, A., Sholehah, K., Irna, N. dan Fistianingrum, W., 2015, Penentuan Parameter Non Spesifik Ekstrak Etanol Kulit Buah Manggis (Garcinia mangostana) Pada Variasi Asal Daerah, Fakultas Farmasi Universitas Ahmad Dahlan, Yogyakarta, Indonesia.

11. Handayani, V., Ahmad, A.R., dan Sudir, M., 2014, Uji Aktivitas Antioksidan Ekstrak Metanol Bunga dan Daun Patikala (Etlingera elatior (Jack) R.M.Sm) Menggunakan Metode DPPH, Pharmaci Science Research, 1(2):86-93.

12. Voight, R., 1994, Buku Pelajaran Teknologi Farmasi, Gadjah Mada University Press, Jogjakarta, Indonesia.

13. Mustarichie R., Mustiroh, I dan levita, J., 2011. Metode Penelitian Tanaman Obat Cetakan Pertama, Widya Padjadjaran, Bandung, Indonesia.

14. Akbar, J. 2008, Pemanfaatan ekstrak bunga kecombrang (Nicolaia speciosa Horan) terhadap penyembuhan infeksi jamur saprolegnia sp pada ikan nila merah.

15. Adrian, P., 2000, Analisis Ekstraktif Tumbuhan Sebagai Sumber Bahan Obat, Universitas Negeri Andalas, Padang, Indonesia.

16. Badan Pengawas Obat Dan Makanan Republik Indonesia, 2014, Peraturan Kepala Badan Pengawas Obat Dan Makanan Republik Indonesia Nomor 12 Tahun 2014 Tentang Persyaratan Mutu Obat Tradisional, Kepala BPOM, Jakarta, Indonesia. 